\title{
Assessment of layer thickness and uniformity in railway embankments with Ground Penetrating Radar
}

\author{
F.M. Fernandes \\ Department of Civil Engineering, University of Minho, Guimarães, Portugal \\ M. Pereira \\ Geotechnique Department, Laboratório Nacional de Engenharia Civil, Lisboa, Portugal \\ A. Gomes Correia \& P.B. Lourenço \\ Department of Civil Engineering, University of Minho, Guimarães, Portugal \\ L. Caldeira \\ Geotechnique Department, Laboratório Nacional de Engenharia Civil, Lisboa, Portugal
}

\begin{abstract}
In the aim of a national research project entitled "Interaction soil-rail track for high speed trains", a protocol was established between the National Railway Network and four national research institutions to develop the knowledge concerning the methodology for the construction and quality control of the railway embankments and railtrack layers for high speed trains. One of the objectives of this protocol is to establish a methodology for quality control of construction layers by different available test methods. Nondestructive testing (NDT) methods are currently very attractive due to their ability to provide information about layer thickness and state condition without causing damage or requiring the removal of material samples. Within the NDT available, ground penetrating radar (GPR) is a very fast and reliable technique, whose advantage is the repeatability and the capability of acquiring continuous data.

To reach the proposed goal, a trial embankment was constructed with different materials, layer's thicknesses, water contents and compaction energy levels. GPR was used in two embankments, in order to detect the thickness of the sub-ballast layer located over the compacted sand layer and its uniformity along the track, but also along the cross-section of the track. In order to control some parameters of the sub-ballast layer, like thickness and uniformity, several metallic plates had been used in the base of the sub-ballast layer, along an alignment. It shows clearly the ability of GPR to detect the sub-ballast layer and its thickness variations along the profile.
\end{abstract}

\section{INTRODUCTION}

In the aim of a national research project entitled "Interaction soil-rail track for high speed trains", it was established a protocol between the National Railway Network (REFER) and four national research institutions to develop the knowledge concerning methodologies for the construction and quality control of railway embankments and rail track layers for high speed trains. One of the objectives is to establish a methodology for quality control of construction layers by different existing test methods.

For this purpose, non-destructive testing (NDT) methods are currently very attractive due to their ability to provide information about layer thickness and state condition without causing damage or requiring the removal of material samples. Within the NDT available, ground penetrating radar (GPR) is a fast and reliable technique, whose advantage is the repeatability and capability of acquiring continuous.

\section{GEORADAR}

The georadar is a non-destructive and non intrusive inspection technique, which principle is based on the radiation of very short electromagnetic impulses $(<10 \mathrm{~ns})$ that are reflected at interfaces of materials with different dielectric properties (Figure 1).

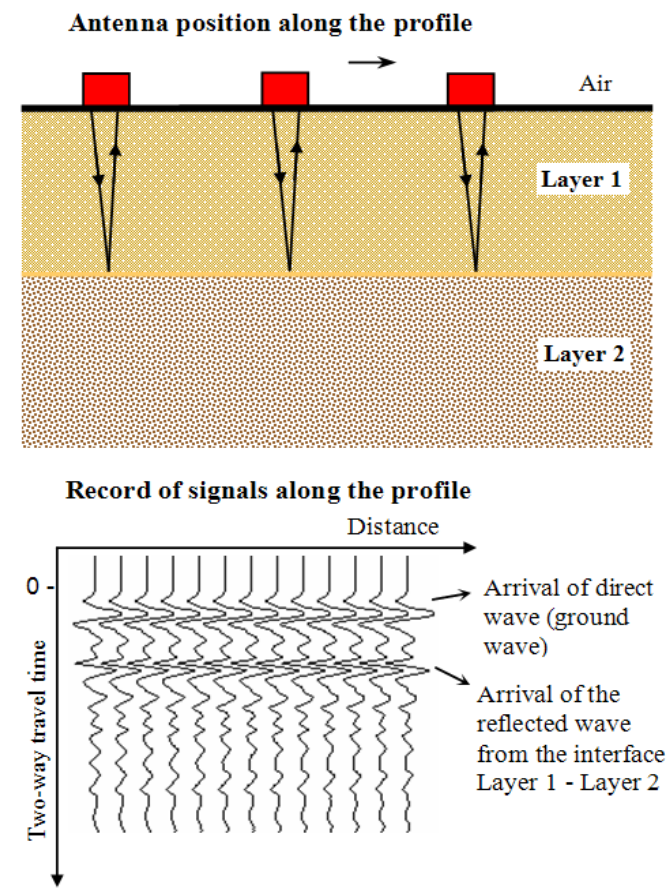

Figure 1 - Working principle of georadar in reflection mode and resultant radargram. 
For applications in civil engineering, usually frequencies from $500 \mathrm{MHz}$ to $2.5 \mathrm{GHz}$ are applied via bow tie antennas. The reflections recorded with the receiving antenna by moving both, transmitter and receiver along a predefined line on the surface can be visualized as 2D images or radargrams, where the intensity of the reflected impulses is displayed in a grey scale.

\section{RAILWAY INVESTIGATION}

The construction of new railway infrastructures and the maintenance and upgrade of existing ones for higher speeds and loads depends greatly on obtaining field information about construction quality, materials characteristics and conditions. For that purpose, ground penetrating radar (GPR) is being actively used and studied for several decades by diverse scientists (Clark et al. 2004, Hugenschmidt 2000, Gallagher et al. 1999, Jack \& Jackson 1999, Roberts et al. 2006). This technique has become an accepted method for in-situ monitoring.

The georadar allows to obtain a significant number of parameters that are very relevant to analyse and assess the conditions of construction layers and embankments. It includes the assessment of the thickness, elastic modulus, dielectric and magnetic properties and the moisture condition of ballast, subballast and base layers (Narayanan et al. 2004, Clark et al. 2001). It also can help in the detection of base or ballast settlements.

GPR has several key characteristics that made it very adequate for the referred purpose. It is a portable and compact equipment, which allows the continuous survey and data acquisition along very large distances and at rather fast speeds (up to $50 \mathrm{~km} / \mathrm{h}$ ). It allows the characterisation of the soil and ballast at large depths (up to $5 \mathrm{~m}$ ), depending on the antenna frequency used. Furthermore, it is significantly faster, more reliable and precise than traditional techniques based on hole drilling, destructive methods or simple visual inspection.

\section{TESTING SITE AND METHODOLOGY}

To reach the proposed goal, a trial embankment was constructed with different materials, layer's thicknesses, water contents and compaction energy levels. Two tracks were built, one constituted by a compacted sand layer and a second one constituted by a sub-ballast layer over a compacted sand layer (see Figure 2). Additionally, on the first track, metallic plates were introduced in the base of the subballast layer, along an alignment, which provides an indicator for thickness control. The surveys were carried out in order to detect the thickness of the sub-ballast layer located over the compacted sand layer and its uniformity along the track and the cross-section of the track.

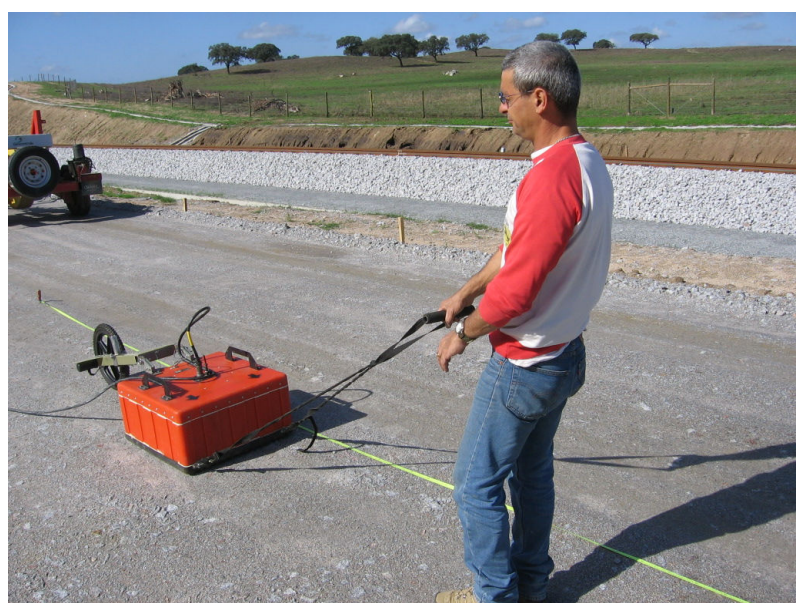

Figure 2 - Partial view of the trial embankment with execution of a GPR profile.

To accomplish this, two GPR systems were used together with different antenna frequencies. One RAMAC system (MALA Geoscience, Inc.) was used together with three different antennas, each one with a different objective: $500 \mathrm{MHz}$ antenna for deep sounding, $800 \mathrm{MHz}$ antenna for optimum detection of the layers in the first half meter and $1600 \mathrm{MHz}$ antenna for the survey of shallow characteristics. A SIR-10 system (Geophysical Survey Systems, Inc.) was used with an antenna of $900 \mathrm{MHz}$, as illustrated in Figure 3.
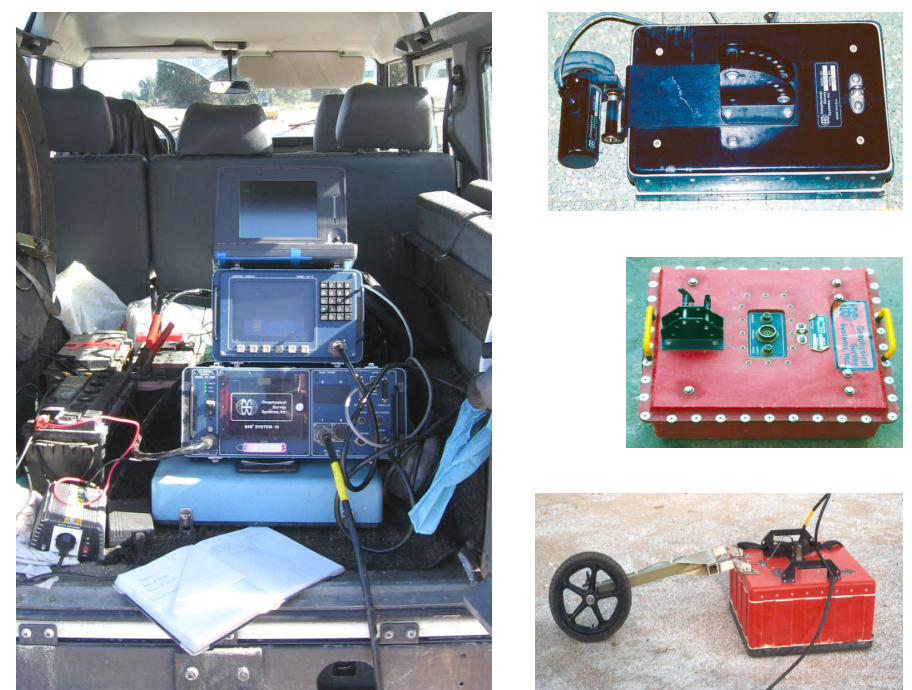

Figure 3 - Equipment: System SIR-10 - GSSI, and antennas of 900, 500 and $200 \mathrm{MHz}$.

\section{RESULTS}

The radargrams obtained with the surveys carried out in the trial embankments showed that GPR provide very good results regarding obtaining information about layer thickness. Both the surveys with low $(500 \mathrm{MHz})$ and medium $(800 \mathrm{MHz})$ frequencies were successful in showing the thickness and evolution of the sub-ballast layer. However, the $800 \mathrm{MHz}$ 
antenna showed more sensitivity. These radargrams are presented in Figure 4 and Figure 5, respectively.

The conditions on site during the survey were wet; therefore, the dielectric constant of the sub- ballast material was estimated to be around 11. With this value it was possible to compute the thickness of the layer, which is presented in Figure 6.

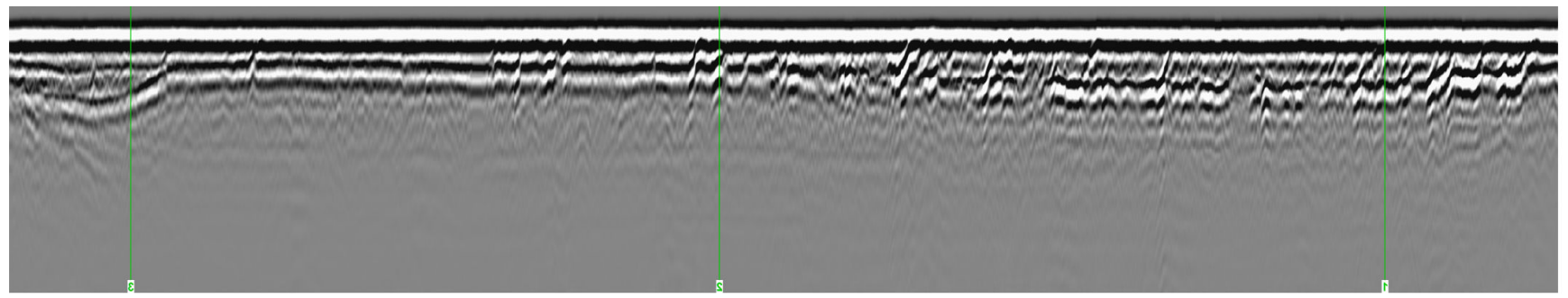

Figure 4 - Partial radargram from the RAMAC system and the $500 \mathrm{MHz}$ antenna.

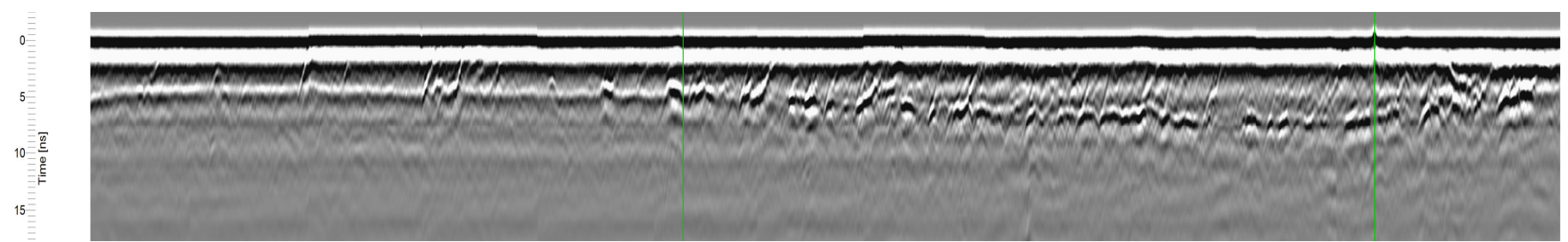

Figure 5 - Partial radargram from the RAMAC system and the $800 \mathrm{MHz}$ antenna.

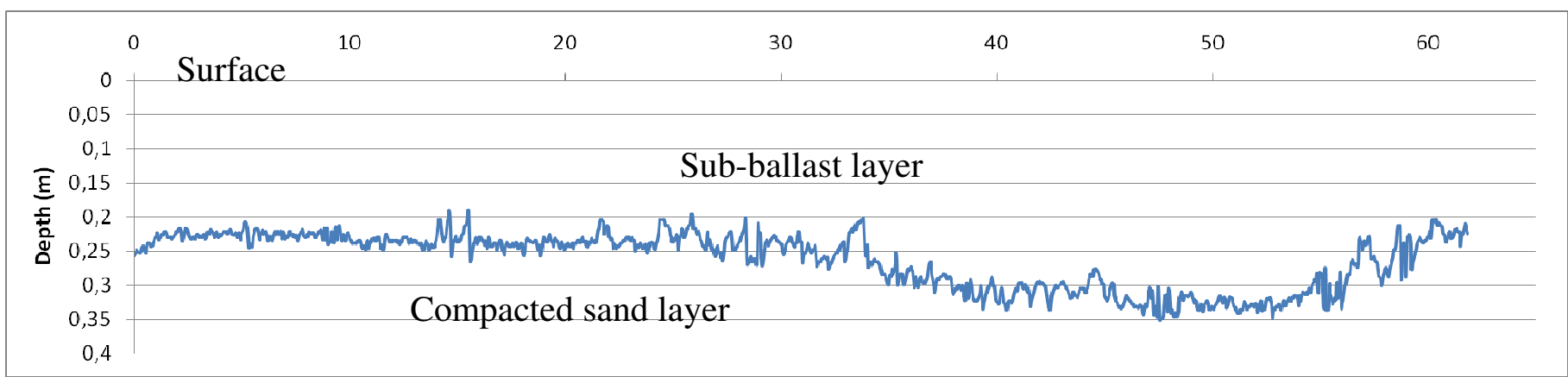

Figure 6 - Evolution of the thickness of the sub-ballast layer obtained with the $800 \mathrm{MHz}$ antenna.

The track was additionally surveyed transversally with the $800 \mathrm{MHz}$ antenna, whose radargram is illustrated in Figure 7. This information complements what was already obtained in previous longitudinal radargrams by showing the thickness evolution through the width of the track section, but also pointing out areas where the contrast is weak, and could be due to the occurrence of fouling or mois- ture. In the same way, the resultant cross-section is illustrated in Figure 8, where it can be seen that the average thickness of the sub-ballast layer is $30 \mathrm{~cm}$ (in the test position) and is rather uniform. In consequence, with this technique, it is rather easy and fast to determine the thickness along a particular track and detect possible defects and anomalies.

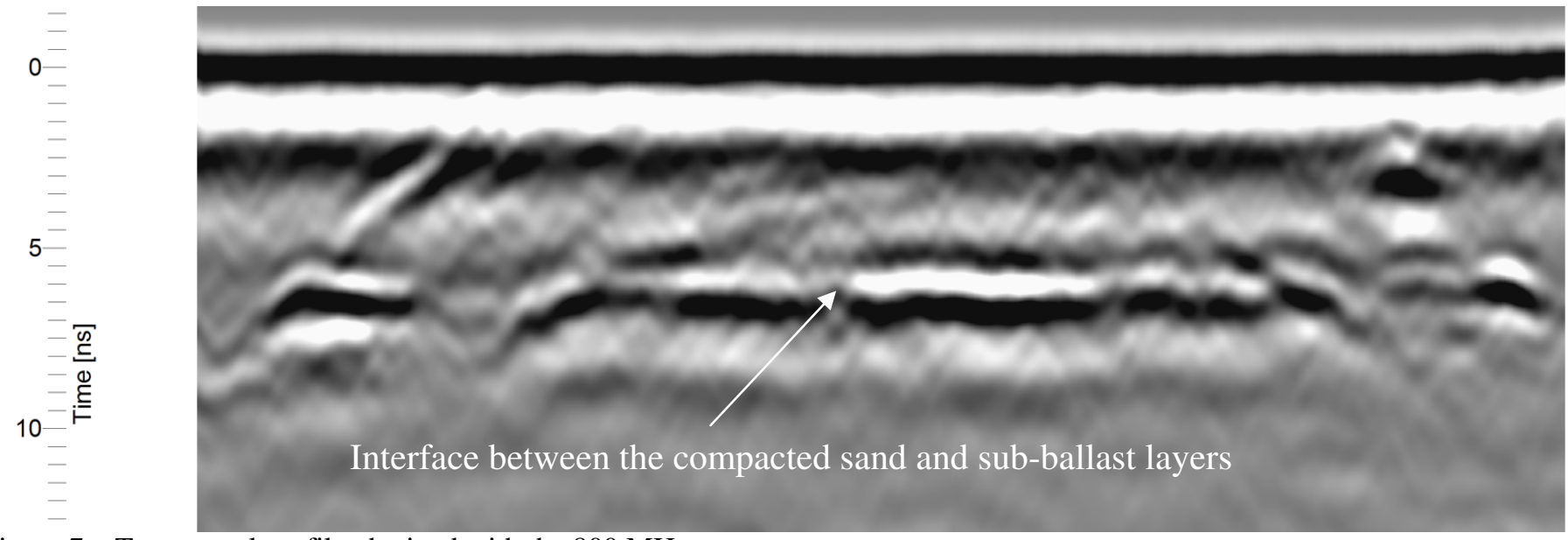

Figure 7 - Transversal profile obtained with the $800 \mathrm{MHz}$ antenna. 


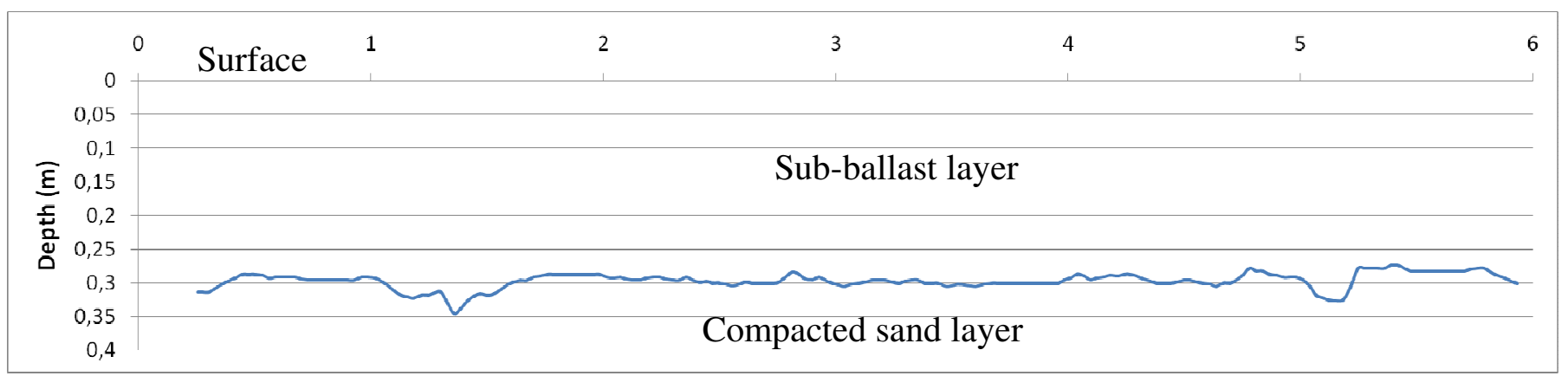

Figure 8 - Cross-section of the embankment from the profile obtained with the $800 \mathrm{MHz}$ antenna.

Other example from a research study using GPR, in a trial embankment, with the system SIR-10 (Geophysical Survey Systems, Inc.) and antennas of $900 \mathrm{MHz}$ is presented in Figure 9.

In order to control some parameters of the subballast layer, like thickness and uniformity, several metallic plates had been used in the base of the subballast layer, along an alignment. Each plate that was placed in the interface between the sub-ballast and the compacted sand layer worked as a reference and was a point of control, due to the fact that metal- lic targets can mark GPR records with multiple and strong reflections. The image in Figure 6 shows clearly the ability of GPR to detect the sub-ballast layer and its thickness variations along the profile. A similar methodology was followed in Carpenter et al. (2004) but, instead of metallic plates, a specially designed high reflectivity polymer band was used instead, providing layer control and speed estimation of the base soil, allowing to control the moisture content evolution.

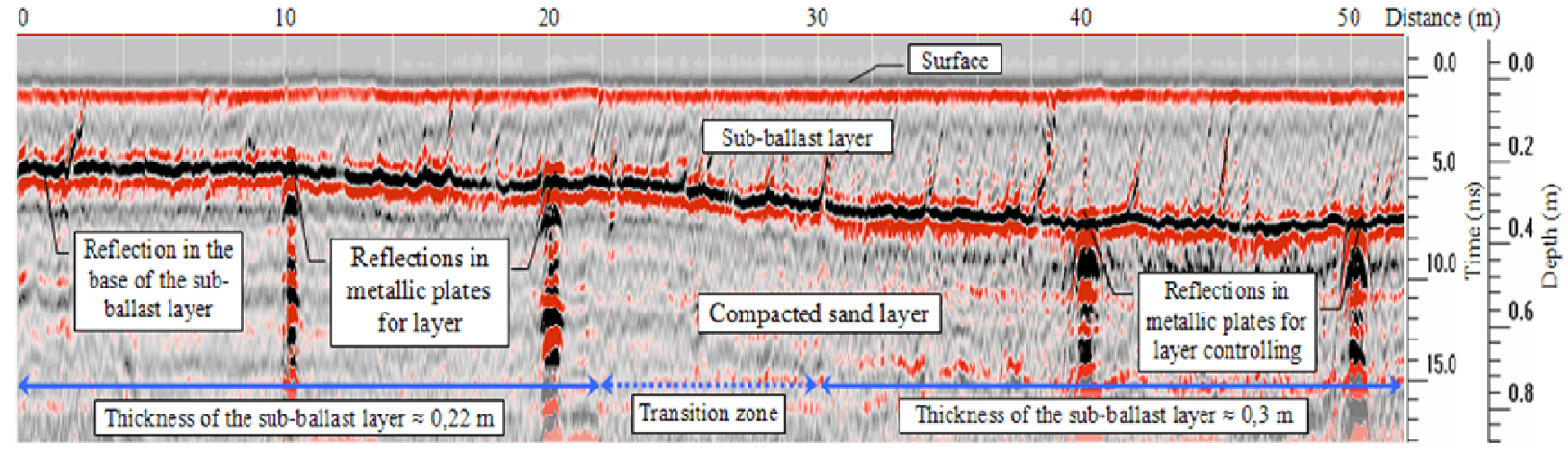

Figure 9 - GPR image obtained with $900 \mathrm{MHz}$ antennas and their interpretation

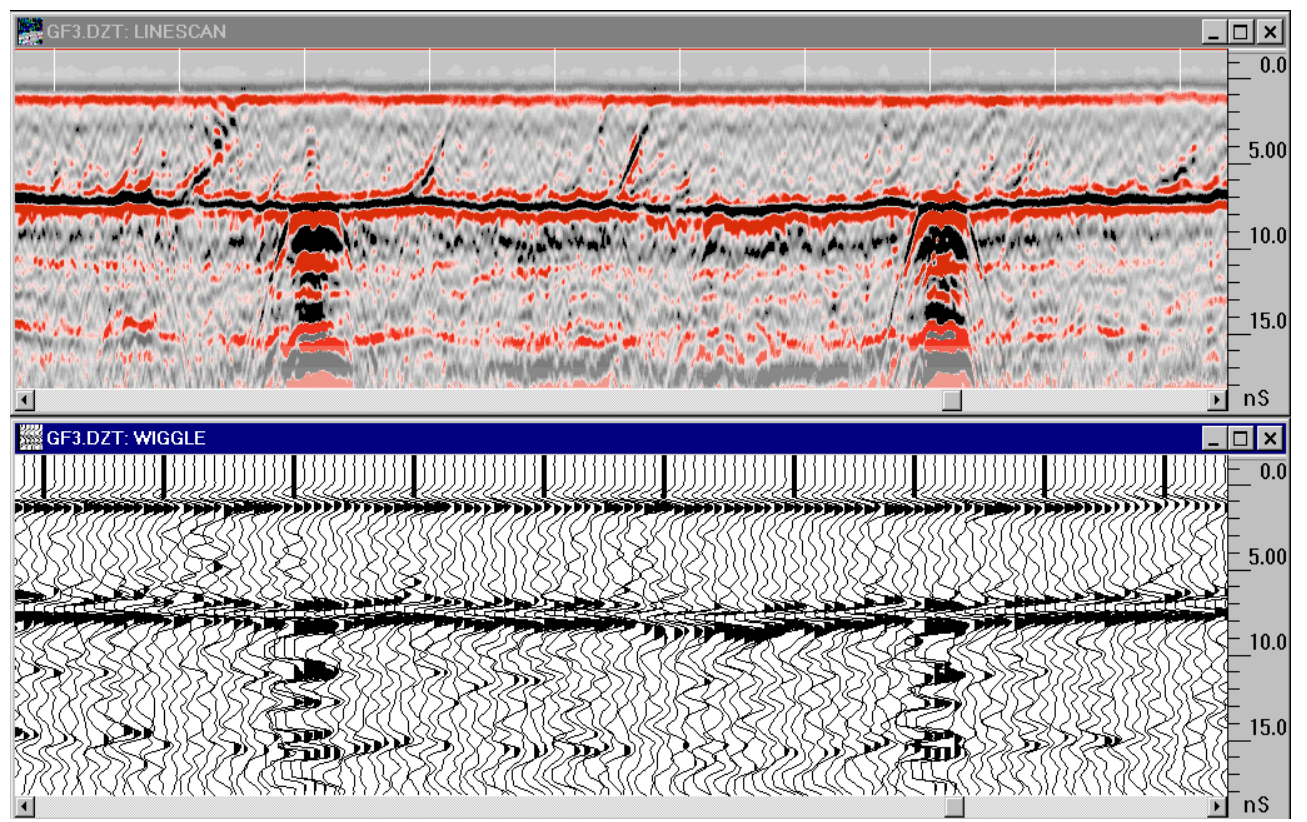

Figure 10 - Radargram with strong signals due the metallic targets in the interface between the sub-ballast and the compacted sand layer. 


\section{CONCLUSIONS}

Georadar was applied in trial railway embankments to validate it's effectiveness in detecting the thickness and evolution of the construction layers. The results showed that the georadar is capable of providing information about the layers thickness, evolution and moisture content, all in a very fast and nondestructive way.

In this way, georadar can be applied during any phase of the construction to verify if the design project is being followed.

\section{ACKNOWLEDGEMENTS}

The authors gratefully acknowledge the National Railway Network (REFER) for building the trial embankments. The second author would like to acknowledge the partial support from FCT (Portuguese Foundation for the Science and Technology) by the grant number POCTI SFRH/BPD/26706/2005.

\section{REFERENCES}

Clark, M.R., Gillespie, R., Kemp, T., McCann, D.M. Forde, M.C. 2001. Electromagnetic properties of railway ballast. NDT\&E International, 34(?):305-311.

Clark, M.R., Gordon, M., Forde, M.C. 2004. Issues over highspeed non-invasive monitoring of railway trackbed. NDT\&E International, 37(?): 131-139.

Roger Roberts, R. Al-Qadi, I., Tutumluer, E., Boyle, J., Sussmann, T. 2006. Advances in railroad ballast evaluation using $2 \mathrm{GHz}$ horn antennas. Proc. $11^{\text {th }}$ International Conference on Ground Penetrating Radar, Columbus Ohio, USA, 19-22 June 2006.

Carpenter, D., Jackson, P.J., Jay, A. 2004. Enhancement of the GPR method of railway trackbed investigation by the installation of radar detectable geosynthetics. NDT\&E International, 37(?): 95-103.

Gallagher, G.P., Leipera, Q., Williamson, R., Clark, M.R., Forde, M.C. 1999. The application of time domain ground penetrating radar to evaluate railway track ballast. NDT\&E International, 32(?): 463-468.

Jack, R., Jackson, P. 1999. Imaging attributes of railway track formation and ballast using ground probing radar. NDT\&E International, 32(?): 457-462.

Hugenschmidt, J. 2000. Railway track inspection using GPR. Journal of Applied Geophysics, 43(?): 147-155.

Narayanan, R.M., Jakub, J.W., Li, D., Elias S.E.G. 2004. Railroad track modulus estimation using ground penetrating radar measurements. NDT\&E International, 37(?): 141-151. 